\title{
Modelling changing catchment under the climate variability: a case study from a semi-arid catchment in the upper basin of the Goulburn River
}

\author{
A. Binesh, I.Y. Yeo \\ School of Engineering, Faculty of Engineering and Built Environment, University of Newcastle \\ Email: ali.binesh@uon.edu.au
}

\begin{abstract}
Hydrological response of arid and semi-arid regions to climate fluctuations are highly variable and predicting induced hydrological variability is extremely challenging. This study investigated the temporal variability of streamflow (SF), and its relationship with soil moisture (SM) in a semi-arid region at the catchment scale, using SWAT (Soil and Water Assessment Tool). SWAT is a continuous semi-distributed model, which simulates the spatial variability of SM, considering the spatial heterogeneity of a catchment such as land cover, soils, and slope, and predicts SF after the routing process. SWAT has been widely used to evaluate the long term impacts of land management practices on water resources in agricultural landscapes.
\end{abstract}

Despite its wide application, the capability of SWAT has not been fully realized in the (semi-) arid region. It is largely because the underpinning concept of SWAT in runoff generation lies on the USDA Soil Conservation Service - curve number (SCS-CN) method. The CN method is limited by its empirical origin. Based on the infiltration loss model, it does not consider long term water losses such as evapotranspiration (ET) and evaporation, the most crucial hydrological term in a water limited environment. Several approaches have been made to improve SM estimation for a continuous modeling (William et al., 2012). The main focus was given to improve estimates of the water retention term (S) based on the soil characteristics (known as Direct Soil Moisture Index, DSMI) or relating it to the potential ET (hence varying it with accumulated plant ET) (referred to as Revised Soil Moisture Index, RSMI).

Considering the potential of improved $\mathrm{CN}$ methods on estimating SM, we apply SWAT to predict and understand hydrologic behaviors of a semi-arid catchment, located within the Goulburn River catchment in the Upper Hunter Region of NSW. The catchment has experienced an extreme climate variability and shown noticeable changes in hydrologic behaviors, in particular SF pattern over last two decades. We report improved hydrological prediction of a changing catchment by: (1) better accounting for the spatial variability of precipitation, soil characteristics, and antecedent SM condition (using DSMI and RSMI methods), and (2) calibrating model parameters over the period of climate fluctuations (both dry and wet periods) for SF. SWAT was set up at a monthly time scale to simulate SM and SF over the period of 2008-2014 using DSMI and RSMI methods. We used SWAT embedded sensitivity analysis and SUFI-2 to calibrate the model over 2008-2012 and validated it over 2013-2014. Calibration contained both wet and dry climatic conditions, however validation only contained the wet period. Sensitivity analysis revealed that both surface runoff and ET were sensitive processes for both the RSMI and DSMI methods to generate SF. However, soil characteristics became sensitive only for DSMI method.

The calibrated model performance for SF estimation was reasonable based on both methods, but RSMI provided improved overall SM prediction. The calibrated models provided NSE (Nash-Sutcliff efficiency) values of $0.60-0.76$ over the calibration and validation periods, with $\sim 11 \%$ of RMSE (root mean squared error). Overall, DSMI method predicted SF slightly better during both of wet and dry period, while RSMI provided better estimation of SM for the study period. In addition, we noted the improvement on the spatial variability of precipitation enhanced SM prediction. Most inconsistent results between simulated and observed SM were from those areas with mismatching soil characteristics between available soil information and actual site conditions. This study shows the potential of using a simple, semi-distributed catchment scale model (calibrated based on SF) to predict SM and SF, and to investigate the threshold for SF generation for the catchment with a changing behaviour in a semi-arid region. Accurate representation of precipitation, climate variations and soil characteristics were crucial to reduce the prediction errors.

Keywords: $\quad$ SWAT, streamflow, soil moisture, semi-arid region, hydrological variability 
Binesh. A and Yeo. I.Y, Modelling changing catchment under the climate variability: a case study from a semiarid catchment in the upper basin of the Goulburn River

\section{INTRODUCTION}

Hydrological response of arid and semi-arid regions to climate fluctuations are highly variable and predicting induced hydrological variability is extremely challenging ( $\mathrm{Li}$ et al., 2009). Most research in semi-arid and arid regions tend to center on quantifying the catchment water balance, i.e., partitioning of precipitation between evapotranspiration and soil water content (SWC), while others focus on identifying the precipitation-runoff relationship. Much research is needed to understand the runoff generation mechanism, linking it back to the spatial and temporal variability of SM.

This study investigated the temporal variability of streamflow (SF) and its relationship with the spatial and temporal dynamics of SM in a semi-arid catchment at the catchment scale, using SWAT (Soil and Water Assessment Tool). It is a continuous semi-distributed model, which simulates SM considering the spatial heterogeneity of a catchment, and predicts SF after the routing process. SWAT has been widely used to evaluate the long term impacts of land management practices on water resources, as it predicts the fate and transport mechanisms of water, nutrients, and other agricultural pollutants from soils to water ways.

Despite its widespread application, the capability of SWAT has not been fully realized in the semi-arid/arid region. It is largely because the underpinning concept of SWAT in runoff generation lies on the USDA Soil Conservation Service - curve number (SCS-CN) method. The CN method is limited by its empirical origin. The precipitation-runoff relationship was mainly developed from the Midwest of USA (i.e., humid region) based on the infiltration loss model, which does not consider long term water losses such as ET and evaporation (Kannan et al, 2008). They are most crucial hydrological component in a water limited environment directly affecting SWC. Several attempts have been made to improve SWC estimation based on the CN method for a continuous modeling (William et al., 2012). The focus was given to improve estimates of the water retention term (S) to a sound, continuous SM accounting procedure (Kannan et al, 2008; William et al., 2012). In particular, improving the $\mathrm{S}$ term based on the soil characteristics (known as Direct Soil Moisture Index, DSMI) or relating it to the potential ET (hence varying it with accumulated plant ET) (referred to as Revised Soil Moisture Index, RSMI) provided better results, when tested for different water resources regions in the US (Kannan et al., 2008). These revised CN methods were embedded in SWAT, and they may provide reasonable SM and SF estimates for a water limited environment such as a southeastern region of Australia.

Considering the success of improved CN methods, we apply SWAT to predict and understand hydrologic behaviors of a semi-arid catchment located within the Goulburn River catchment, in the Upper Hunter Region NSW. The catchment experienced extreme climate variability and showed noticeable changes in hydrologic behaviors, in particular SF pattern. We report improved hydrological prediction of a changing catchment by: (1) better accounting for the spatial variability of precipitation, soil characteristics and antecedent SM condition (i.e., DSMI and RSMI methods), and (2) calibrating model parameters over the period of climate fluctuations (both dry and wet periods) for SF.

\section{MATERIALS AND METHODS}

\subsection{Study Area}

The study was conducted on the Merriwa sub-catchment (with areal size of $651 \mathrm{~km}^{2}$ ), situated in northern part of the Goulburn catchment in the Upper Hunter Region, NSW (Fig. 1). The area was mostly covered by tertiary basalt soils, thick clay layers, and dominantly used for grazing. This semi-arid catchment experienced extreme climate fluctuations and seasonal variability. Over last 10 or more years, precipitation varied highly. The monthly precipitation recorded for Aug-2005 was $10 \mathrm{~mm}$ and for Jun-2008 was $263 \mathrm{~mm}$. Moreover, long time series average of precipitation shows that 19.28 $\mathrm{mm}$ for August and $64.88 \mathrm{~mm}$ for December. Moreover, precipitation varied spatially

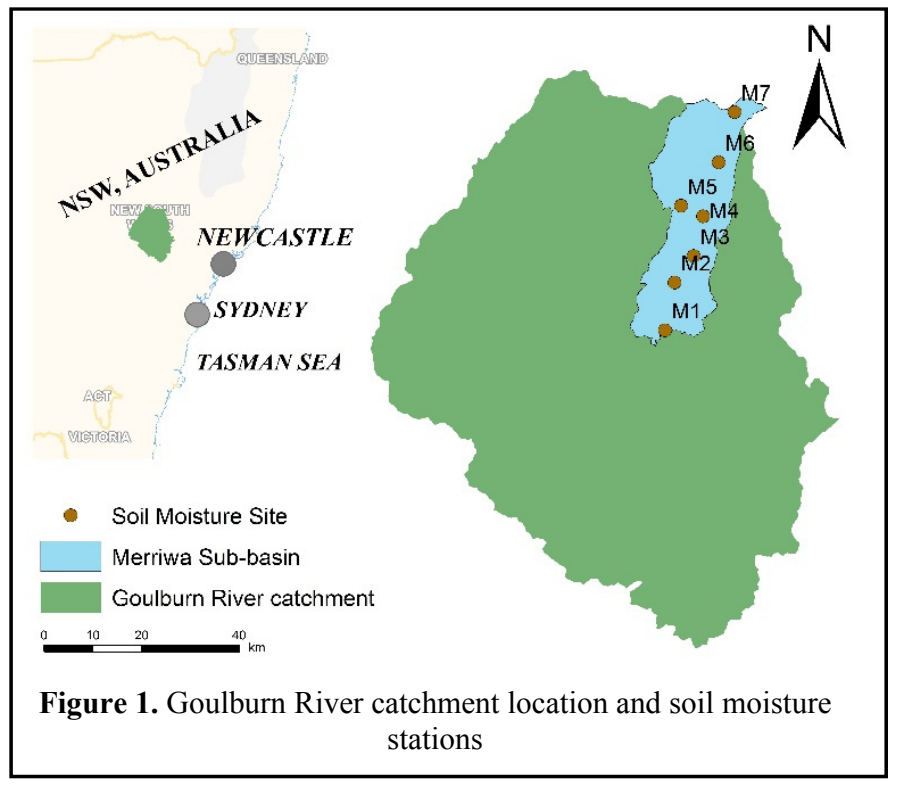
between the north and southern area with a large change in elevations. The catchment elevation reduced from 
Binesh. A and Yeo. I.Y, Modelling changing catchment under the climate variability: a case study from a semiarid catchment in the upper basin of the Goulburn River

$1100 \mathrm{~m}$ at the northern ridge to $200 \mathrm{~m}$ near the catchment outlet, and the long-term average of annual precipitation ranged from $814 \mathrm{~mm}_{\text {year }}^{-1}$ in M7 site to $442 \mathrm{~mm}_{\text {year }}{ }^{-1}$ in M1 site. A dense network of SM and SF monitoring stations established in the study area provided invaluable information to characterize the spatial and temporal dynamics of SM and SF. The monitoring effort was established under the SASMAS (Scaling and Assimilation of Soil Moisture And Stream Flow) project since 2002, with an aim to develop a scaling relationship between point measurements to areal estimates and to investigate the spatial distribution of root zone SM and SF generation processes (Hemakumara et al., 2004). The Merriwa sub-catchment contains seven SM stations, which measure SM at depths of 0-30 cm, 30-60 cm, and 60-90 cm using Campbell Scientific CS616 water content reflectometers. Additionally, all SM monitoring sites were recently upgraded with tipping bucket rain gauges. SF was monitored at the catchment outlet over 2002-2016 at a daily time scale. Recorded SF showed dramatic changes from its usual range of $<0.01 \mathrm{~m}^{3} \mathrm{~s}^{-1}$ up to $150 \mathrm{~m}^{3} \mathrm{~s}^{-1}$ during the monitoring period. The Merriwa sub-basin experienced extreme drought and hot weather condition from 2000 till end of 2010 (known as the Millennium drought), followed by increasing precipitation and wet conditions.

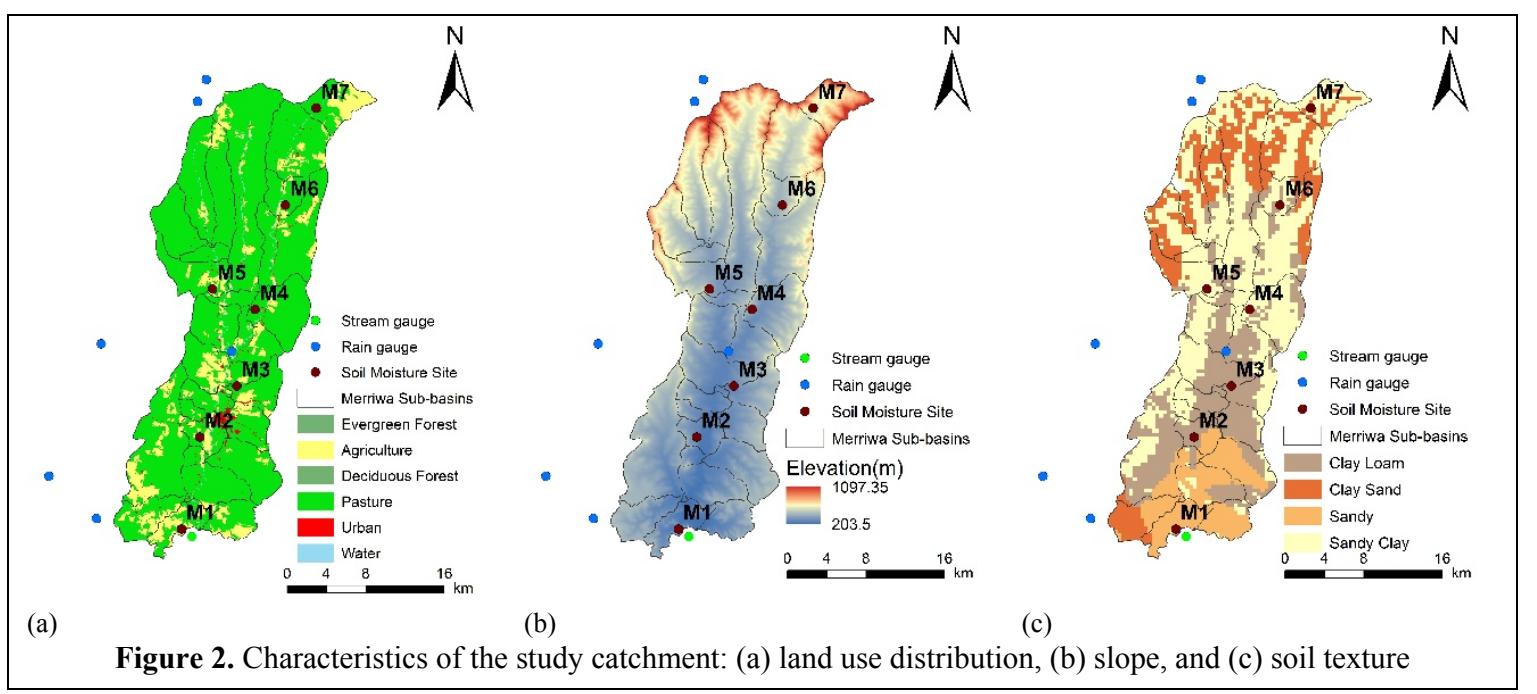

\subsection{Data and Method: SWAT model and Data collection}

SWAT is a continuous, spatially (semi-) distributed model (Arnold et al., 1998). The model first divides the catchment into sub-basin, which is further discretized into a series of hydrologic response units (HRUs). HRUs are determined by a unique combination of soil, land use and slope (Figures 2a, 2b, 2c). All hydrologic processes are simulated first for each HRU, and aggregated and routed to each sub-basin and then to the entire catchment. The hydrological cycle in SWAT is based on the water balance equation:

$$
\frac{\partial S W C}{\partial t}=P_{\text {day }}-Q_{\text {surf }}-E T_{a}-w_{\text {seep }}-Q_{g w}
$$

where $P_{\text {day }}$ is the precipitation rate $\left(\mathrm{mm} \mathrm{d}^{-1}\right), \mathrm{Q}_{\text {suf }}$ is the $\mathrm{SF}$ rate $\left(\mathrm{mm} \mathrm{d}^{-1}\right), \mathrm{E}_{\mathrm{a}}$ is actual evapotranspiration (AET) rate $\left(\mathrm{mm} \mathrm{d}^{-1}\right), \mathrm{W}_{\text {seep }}$ is the water percolation rate from the soil profile $\left(\mathrm{mm} \mathrm{d}^{-1}\right)$, and $\mathrm{Q}_{\mathrm{gw}}$ is the groundwater flow rate $\left(\mathrm{mm} \mathrm{d}^{-1}\right)$. The $\mathrm{SF}$ and storage terms $(\mathrm{S})$ are estimated based on the $\mathrm{CN}$ method, as:

$$
\begin{aligned}
& Q_{\text {surf }}=\frac{\left(P_{\text {day }}-0.2 S\right)^{2}}{\left(P_{\text {dav }}+0.8 S\right)}, P_{\text {day }}>0.2 S \text { and } Q_{\text {surf }}=0, P_{\text {day }}<0.2 S \\
& S=254\left(\frac{100}{C N}-1\right)
\end{aligned}
$$

where $\mathrm{S}$ is the retention parameter $\left(\mathrm{mm} \mathrm{d}^{-1}\right)$.

Several attempts have been made to improve the $\mathrm{CN}$ method by correcting $\mathrm{S}$ for a continuous modeling. DSMI, for example, calculates S based on soil characteristics, including field capacity (FC), wilting point (WP), saturated condition (SAT), and SWC over the soil profile (Williams and LaSeur, 1976), as:

$$
S=S_{\max } \cdot\left(1-\left(\frac{S W C}{S W+\exp \left(w_{1}-w_{2} \cdot S W C\right)}\right)\right.
$$

where, 
Binesh. A and Yeo. I.Y, Modelling changing catchment under the climate variability: a case study from a semiarid catchment in the upper basin of the Goulburn River

$$
\begin{aligned}
& w_{1}=\ln \left(\frac{F C}{\left(1-S_{3} \cdot S_{\text {max }}^{-1}\right)}-F C\right)+w_{2} \cdot F C \\
& w_{2}=\ln \left(\frac{F C}{\left(1-S_{3} \cdot S_{\max }^{-1}\right)}-F C\right)-\ln \left(\frac{S A T}{\left(1-2.54 \times S_{\max }\right)}-S A T\right)(S A T-F C)^{-1}
\end{aligned}
$$

where $S_{\max }$ is the maximum value of the retention parameter $S$ can achieve on any given day $\left(\mathrm{mm} \mathrm{d}^{-1}\right), \mathrm{w}_{1}$ and $\mathrm{w}_{2}$ are the shape coefficients, and $\mathrm{S}_{3}$ is the retention parameter for the moisture condition III (i.e., wet condition). $\mathrm{S}_{\max }$ is calculated based on the moisture condition I (i.e., dry condition) using Equation (3).

However, DSMI tends to overestimate SM for soils with lower soil water storage capacity (e.g., shallow or course textured soils), as it allows soils to become saturated quickly. Hence, RSMI was developed to relate SWC to accumulated antecedent climatic conditions, making it more dependent on potential evapotranspiration (PET) rather than soil properties (Williams et al., 2012) (Eq. 7), as:

$$
S_{t}=S_{t-1}+P E T \exp \left(-B \times \frac{S_{t-1}}{S_{\max }}\right)-P_{t}+Q_{t}
$$

where $\mathrm{S}_{\mathrm{t}}$ and $\mathrm{S}_{\mathrm{t}-1}$ are the retention at time steps $\mathrm{t}$ and $\mathrm{t}-1$, and $\mathrm{B}$ is the depletion coefficient. In SWAT, PET can be estimated using different methods such as Penman-Monteith (PM) or Hargreaves method. We used PM method for this study.

\subsection{SWAT model Setup and experiment design}

Several geospatial information and hydrological data sets are required for SWAT. All the necessary spatial datasets and input database files for the model were organized and prepared based on the guidelines of SWAT2005 version (Winchell et al., 2009). Table (1) summarizes data sources for SWAT model.

Table 1. Data sources for the SWAT model

\begin{tabular}{ll}
\hline Data & Source \\
\hline Digital Elevation Model (DEM) & SRTM-derived 1 Second Digital Elevation Models, Geoscience of Australia \\
\hline Soil & $\begin{array}{c}\text { Atlas of Australian Soils from Australian Soil Resource Information System (ASRIS) and Soil } \\
\text { Grid Map from Soil and Landscape Grid of Australia (http://www.clw.csiro.au) }\end{array}$ \\
\hline Land Use & Australian Bureau of Agricultural and Resource Economics and Sciences (ABARES) \\
\hline Climate & Australian Government, Bureau of Meteorology and Scaling and Assimilation of Soil Moisture \\
& And Streamflow project (SASMAS) \\
\hline Streamflow & Department of Primary Industries-Office of Water \\
\hline Soil Moisture & Scaling and Assimilation of Soil Moisture And Streamflow project (SASMAS project) \\
\hline
\end{tabular}

The model was set up to represent improved weather and soil distribution, in particular to have better representation of the spatial variability. First, we extrapolated weather information from 9 raingauges and re-delineated the sub-basin boundary to capture the precipitation distribution. In SWAT, each sub-basin was assumed to have the same weather condition. For example, M4, M6 and M7 were located within one sub-basin from the initial watershed delineation, but in the revised one, each was separately located into different subbasins. Re-delineation increased the number of the sub-basins from 20 to 31 . We noted that total error percent of precipitation estimation from the initial watershed delineation for M7 site was $37.2 \%$, but it was reduced to zero with re-delineation. For soil data, we used both Soil Atlas Map and recently published Soil Grid.

Then, model was setup to evaluate DSMI and RSMI method for the SM and SF prediction separately, while calibrating SWAT against SF under both setups. The SWAT simulations were conducted at a monthly time step over 2008-2014, with a 2-year warm-up (20062007), a 5-year calibration (2008-2012), and a 2-year validation (2013-2014). Calibration period contained wet and dry weather conditions, however validation contained wet period only. The calibration was based on 17 parameters selected based on previous studies (Akhavan et al., 2010), after the sensitivity analysis. The SUFI-2 stochastic semi-auto calibration approach (Abbaspour, et al., 2015) was performed on all of the 17 parameters, with an objective function to improve Nash-Sutcliff Efficiency (NSE) 
Binesh. A and Yeo. I.Y, Modelling changing catchment under the climate variability: a case study from a semiarid catchment in the upper basin of the Goulburn River

coefficient. Simulation results were compared against in situ observations of SM and SF, and the model performance metrics such as Root Mean Square Error (RMSE) and Correlation of Coefficient $\left(\mathrm{R}^{2}\right)$ were calculated to estimate the model errors.

\section{RESULT AND DISCUSSION}

The model was set up to meet the model performance criteria for SF, as outlined by Moriasi et al. (2007). The sensitivity analysis showed that parameters related to surface runoff and evapotranspiration were sensitive for both methods, but soil characteristic became more sensitive for DSMI as expected. Calibration provided different values for common sensitive parameters, as it was done separately. DSMI method determined the ground water level more deeper $(10.7 \mathrm{~m})$ than RSMI method $(3 \mathrm{~m})$. Moreover, parameters related to soil characteristics were given higher values (e.g., soil hydraulic conductivity $=0.42 \mathrm{~mm} \mathrm{hr}^{-1}$ ) in DSMI method compared to RSMI method (e.g., soil hydraulic conductivity $=0.12 \mathrm{~mm} \mathrm{hr}^{-1}$ ). However, parameters related to vegetation such as maximum canopy capacity, had higher values in RSMI method (Maximum Canopy Storage $=65$ ) compared to DSMI method (Maximum Canopy Storage=6.8), as they affected ET.

The model performance statistics are presented in Table (2). Fig (4) \& (5) showed predicted stream flow under DSMI and RSMI methods over the monitoring period. Both DSMI and RSMI provided satisfactory results when evaluated against SF, though DSMI

\begin{tabular}{|c|c|c|c|}
\hline \multicolumn{4}{|c|}{ Table 2. Model Performance Measures for Stream Flow during } \\
Calibration (a) and Validation (b) Period \\
\hline Method & NSE & RMSE $\left(\mathrm{m}^{3} \mathrm{~s}^{-1}\right)$ & $\mathrm{R}^{2}$ \\
\hline DSMI & {$\left[0.65^{\mathrm{a}} 0.76^{\mathrm{b}}\right]$} & {$\left[0.83^{\mathrm{a}} 1.03^{\mathrm{b}}\right]$} & {$\left[0.44^{\mathrm{a}} 0.83^{\mathrm{b}}\right]$} \\
\hline RSMI & {$\left[0.60^{\mathrm{a}} 0.72^{\mathrm{b}}\right]$} & {$\left[0.87^{\mathrm{a}} 1.09^{\mathrm{b}}\right]$} & {$\left[0.43^{\mathrm{a}} 0.96^{\mathrm{b}}\right]$} \\
\hline
\end{tabular}
produced more slightly better result. As Fig.4 shows, the DSMI captured high flows more accurately than RMSI, however RSMI performed better for low flows. Due to the dependency of RSMI on PET, RSMI underestimated SF over high PET period, while DSMI overestimated low flow. Surprisingly, both methods captured SF characteristics during the transition between dry to wet period. Fig.5 represents the cumulative runoff for both RSMI and DSMI methods compared to cumulative observed runoff. SF results showed that till late 2010 RSMI produced streamflow better, however the increasing SF trend with wetter condition after 2010 were better captured by DSMI. The performance statistics were more accurate during validation, as it included only wet condition (Table 2). Overall, the performance statistics showed the calibrated parameters provided reasonable simulation under both wet and dry conditions.

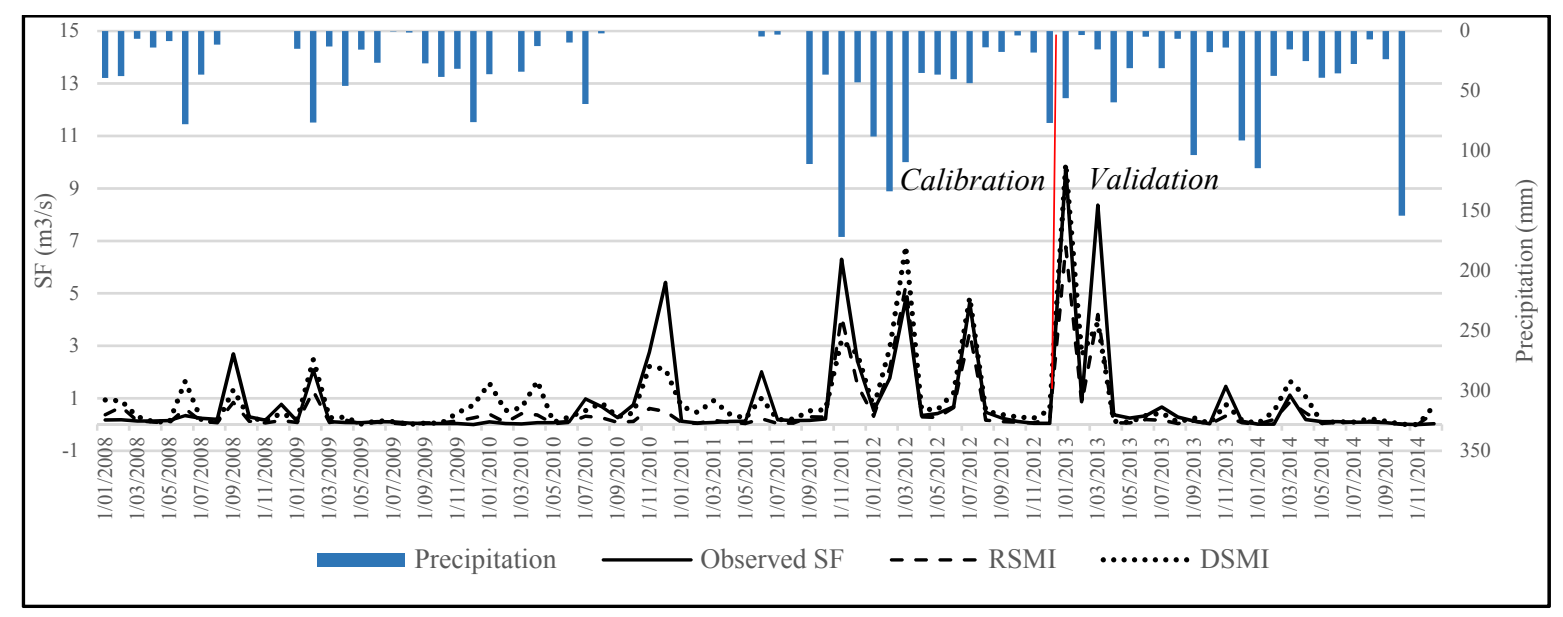

Figure 4. Simulated Streamflow under DSMI and RSMI methods 
Binesh. A and Yeo. I.Y, Modelling changing catchment under the climate variability: a case study from a semiarid catchment in the upper basin of the Goulburn River

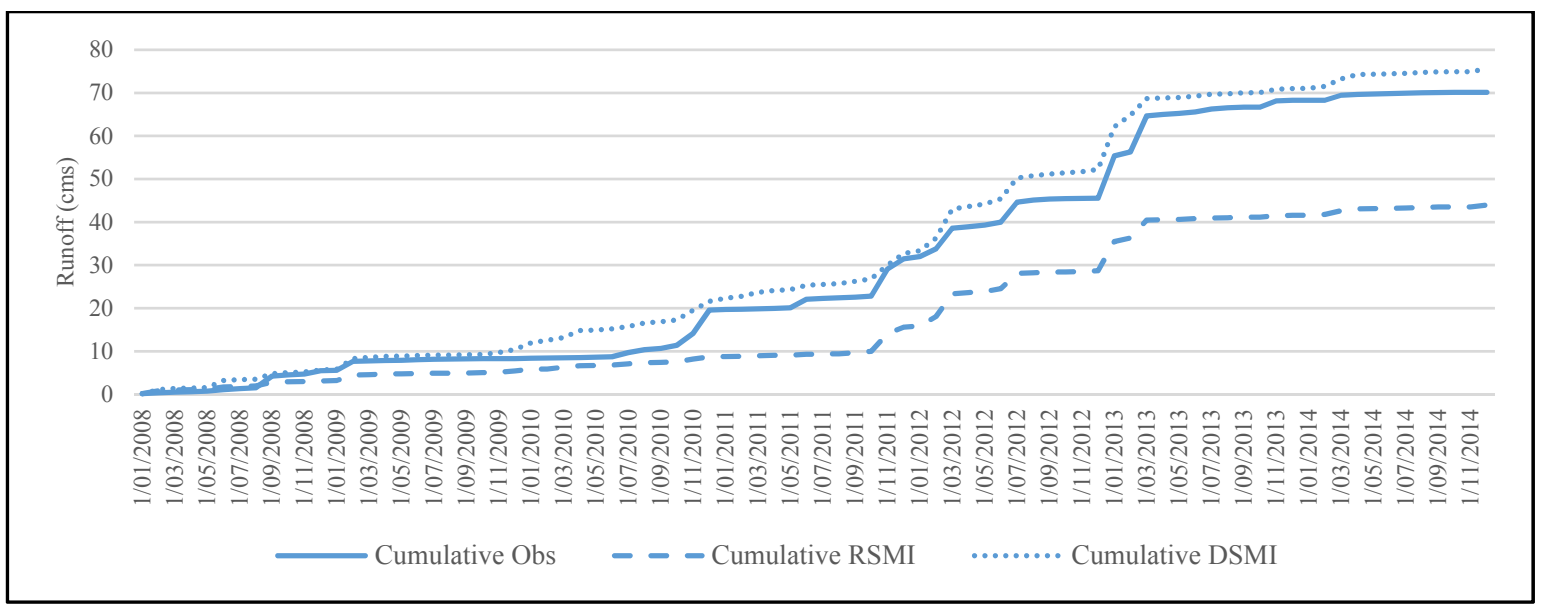

Figure 5. Cumulative stream flow simulated with RSMI and DSMI methods compared to observed runoff

Predicted sub-basin scale SM was compared against in-situ SM. Each sub-basin including SM monitoring sites was set up to have the same, uniform precipitation as observed at each SM site. In addition, soil characteristics within each subbasin showed more less similar, without much spatial variation. Soil depth at each of the sites vary so the whole soil profile for each in-situ SM compared to SM

\begin{tabular}{|l|l|c|c|c|}
\hline \multicolumn{5}{|c|}{ Table 3. Predicted sub-basin scale SM during Calibration (a) and Validation (b) } \\
Period \\
\hline \multirow{2}{*}{$\begin{array}{l}\text { SM } \\
\text { Site }\end{array}$} & \multicolumn{2}{|c|}{ RMSE (\%) } & \multicolumn{2}{c|}{$\mathrm{R}^{2}$} \\
\cline { 2 - 6 } & DSMI & RSMI & DSMI & RSMI \\
\hline M1 & {$\left[5^{\mathrm{a}} 3^{\mathrm{b}}\right]$} & {$\left[6^{\mathrm{a}} 3^{\mathrm{b}}\right]$} & {$\left[0.41^{\mathrm{a}} 0.45^{\mathrm{b}}\right]$} & {$\left[0.44^{\mathrm{a}} 0.46^{\mathrm{b}}\right]$} \\
\hline M2 & {$\left[10^{\mathrm{a}} 2^{\mathrm{b}}\right]$} & {$\left[7^{\mathrm{a}} 7^{\mathrm{b}}\right]$} & {$\left[0.08^{\mathrm{a}} 0.41^{\mathrm{b}}\right]$} & {$\left[0.12^{\mathrm{a}} 0.2^{\mathrm{b}}\right]$} \\
\hline M3 & {$\left[28^{\mathrm{a}} 13^{\mathrm{b}}\right]$} & {$\left[11^{\mathrm{a}} 9^{\mathrm{b}}\right]$} & {$\left[0.13^{\mathrm{a}} 0.9^{\mathrm{b}}\right]$} & {$\left[0.08^{\mathrm{a}} 0.15^{\mathrm{b}}\right]$} \\
\hline M4 & {$\left[15^{\mathrm{a}} 14^{\mathrm{b}}\right]$} & {$\left[10^{\mathrm{a}} 10^{\mathrm{b}}\right]$} & {$\left[0.04^{\mathrm{a}} 0.17^{\mathrm{b}}\right]$} & {$\left[0.07^{\mathrm{a}} 0^{\mathrm{b}}\right]$} \\
\hline M5 & {$\left[11^{\mathrm{a}} 8^{\mathrm{b}}\right]$} & {$\left[10^{\mathrm{a}} 4^{\mathrm{b}}\right]$} & {$\left[0.09^{\mathrm{a}} 0.43^{\mathrm{b}}\right]$} & {$\left[0^{\mathrm{a}} 0.47^{\mathrm{b}}\right]$} \\
\hline M6 & {$\left[10^{\mathrm{a}} 9^{\mathrm{b}}\right]$} & {$\left[6^{\mathrm{a}} 8^{\mathrm{b}}\right]$} & {$\left[0.49^{\mathrm{a}} 0.17^{\mathrm{b}}\right]$} & {$\left[0.48^{\mathrm{a}} 0.14^{\mathrm{b}}\right]$} \\
\hline M7 & {$\left[8^{\mathrm{a}} 7^{\mathrm{b}}\right]$} & {$\left[4^{\mathrm{a}} 2^{\mathrm{b}}\right]$} & {$\left[0.38^{\mathrm{a}} 0.51^{\mathrm{b}}\right]$} & {$\left[0.55^{\mathrm{a}} 0.55^{\mathrm{b}}\right]$} \\
\hline
\end{tabular}
from the model at the same depth. Table 3 showed SM prediction was made within 10\% error compared to in-situ, except M3, M4, and M5 sites. The large discrepancy seemed to be caused by errors in representing soil characteristics and precipitation. For instance, both M2 and M4 sites did not have in-situ rain gauge station, so the precipitation was interpolated using the dataset from the nearest station. Since the Merriwa sub-basin has a high spatial variability of precipitation, extrapolated and interpolated precipitation could lead to a large error in SM prediction. Furthermore, we noted inconsistency in soil information shown in Soil Grid and Soil Atlas Map when compared to in-situ soil samples. For example, the lab analysis showed M3, M4, and M5 are as clay loam, loam, and clay soil. However, in soil database, they were all mapped as sandy clay soils (more than $60 \%$ sand). Thus, large differences in soil and precipitation for these sites led to large prediction errors.

While both methods met the model performance criteria based on SF, it was clear that RSMI provided better $\mathrm{SM}$ prediction, in terms of the overall trend (as shown from $\mathrm{R}^{2}$ ) and accuracy (indicated by RMSE). It highlights the importance of cumulative PET, i.e., the prior climatic condition, on estimating SM for the semiarid region. Similar to SF prediction, SM prediction was better for validation period, when prediction was made only for the wet condition. Fig (6) shows SM measured and predicted at M7 site using both methods. As discussed above, DSMI showed SM responded quickly to precipitation events. However, by correcting S based on PET using RSMI, this overestimation became corrected. Fig (6) showed RSMI predicted SM more reasonably than DSMI, in particular during the wet period. Based on our investigating on SF and SM over the fluctuating climate conditions, it can be concluded that RSMI method is more efficient during wet period while DSMI method provides more reasonable SM prediction during dry period. It was because RSMI relying on PET over-corrected the antecedent SM condition, resulting in much less SM prediction. On the other hand, AET was much less than PET due to limited water availability, hence this overestimation could be corrected if RSMI were modified to adjust S term based on AET to reflect more realistic antecedent SM condition.

Consequently, statistics results of SM indicate more accurate investigation of SM based on RSMI method compare to DSMI method during both calibration and validation period. The results show lower RMSE for RSMI method compare to DSMI method. Furthermore, the model accuracy increased by using more precise input data and errors reduce significantly. 
Binesh. A and Yeo. I.Y, Modelling changing catchment under the climate variability: a case study from a semiarid catchment in the upper basin of the Goulburn River

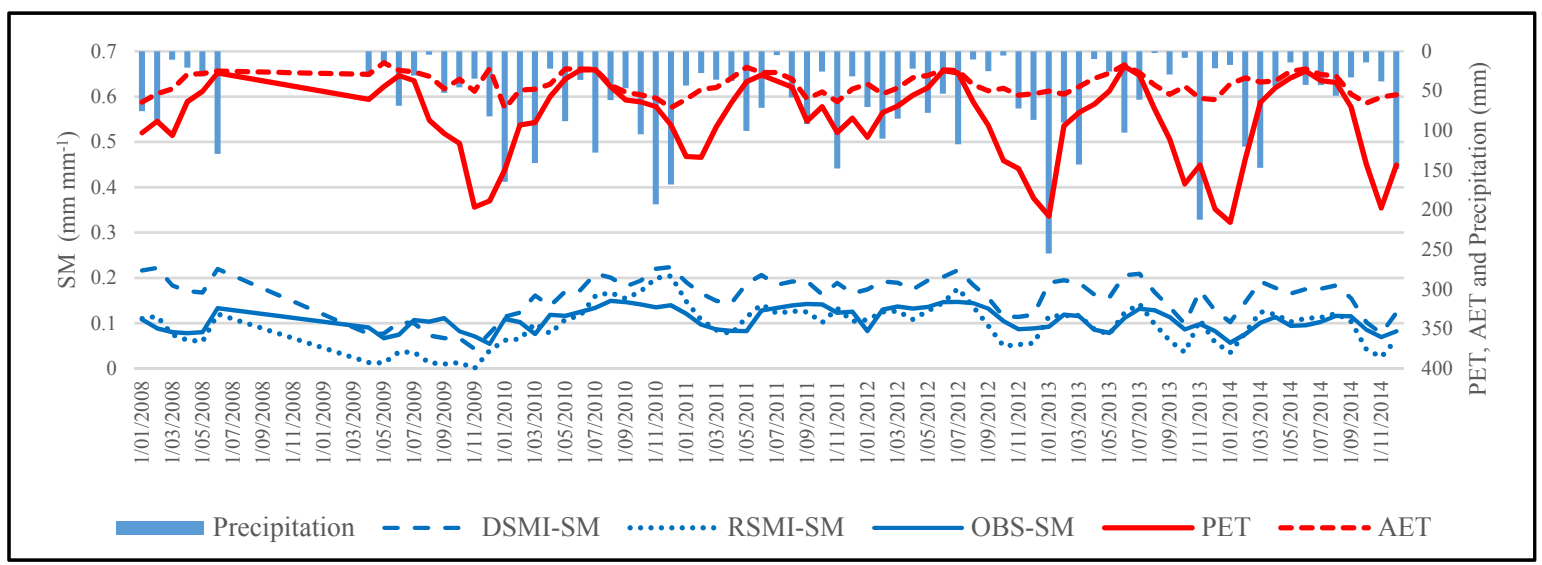

Figure 6. SM prediction for M7 site

\section{CONCLUSIONS}

This study investigated the use of the SCS-CN based SWAT model to predict SM and SF for the agricultural catchment located in the semi-arid region. The catchment experienced fluctuating climate conditions from prolong dry to recent wet conditions, and exhibited more stable, continuous SF in recent years. To provide continuous prediction for SF and associated SM, the CN method in SWAT was improved to better account for soil characteristics and cumulative PET with DSMI and RSMI methods. We calibrated SWAT for both dry and wet periods against SF, using both methods for SM and SF prediction, with improved precipitation and soil characteristics dataset. Both calibrated models provided reasonable prediction for SF and SM. Overall, RSMI provided improved simulation over the dry period for both of the variables (SM and SF), while DSMI made better prediction over the wet period for SF. Our results also suggested large prediction errors were attributed from limited precipitation information and inaccurate soil information. Due to high dependency of hydrologic variables to input data ( $\mathrm{Li}$ et al., 2009), preparation of accurate input dataset is so crucial for having reasonable outputs. For further studies, we will investigate use of cumulative AET instead of PET in RSMI method to reduce the underestimation of SM by correcting antecedent SM conditions to reflect more realistic, actual conditions. Moreover, we will explore the relative impacts of model calibration for both SM and SF on predicting hydrological behaviors of a changing catchment, to better capture the interaction between SM and $\mathrm{SF}$, and SF generating threshold from SM conditions.

\section{REFERENCES}

Abbaspour, K. (2015). SWAT-CUP 2012: SWAT Calibration and Uncertainty Programs: A User Manual. Department of Systems Analysis. Integrated Assessment and Modelling (SIAM), Eawag, Swiss Federal Institute of Aquatic Science and Technology, Duebendorf, Switzerland.

Akhavan, S., Abedi-Koupai, J., Mousavi, F., Afyuni, M., Eslamian, S., and Abbaspour, K.C. (2010). Application of SWAT model to investigate nitrate leaching in Hamadan-Bahar Watershed, Iran. Agriculture, Ecosystems and Environment, 139, 675-688.

Arnold, J.G., Srinivasan, R., Muttiah, R.S., and Williams, J.R. (1998). Large area hydrologic modeling and assessment Part 1: Model development. American Water Resources Association, 89, 34-73.

Hemakumara, M., Kalma, J., Walker, J., and Willgoose, G. (2004). Downscaling of low resolution passive microwave soil moisture observations, in Proceedings of the 2nd international CAHMDA workshop on: The Terrestrial Water Cycle: Modelling and Data Assimilation Across Catchment Scales, edited by A.J. Teuling, H. Leijnse, P.A. Troch, J. Sheffield and E.F. Wood, pp. 67-71, Princeton, NJ, October 25-27

Kannan, N., Santhi, C., Williams, J.R., and Arnold, J.G. (2008). Development of a continuous soil moisture accounting procedure for curve number methodology and its behavior with different evapotranspiration methods. Hydrological process, 22, 2114-2121.

Li, Z., Li, WZ., Zhang, XC., and Zheng, FL. (2009). Impacts of landuse change and climate variability on hydrology in an agricultural catchment on the Loess Plateau of China. Hydrology, 377, 35-42.

Moriasi, D.N., Arnold, J.G., Van Liew, M.W., Bingner, R.L., Harmel, R.D., and Veith, T.L. (2007). Model evaluation guidelines for systematic quantification of accuracy in watershed simulations. Transactions of the ASABE, 50, 885900.

Williams, J. R., and LaSeur, W.V. (1976). Water yield model using SCS curve numbers. Hydraulic Engineering, 102, $1241-1253$.

Williams, J. R., Kannan, N., Wang, X., Santhi, C., and Arnola, J. G. (2012). Evolution of the SCS runoff curve number method and its application to continuous runoff simulation. Hydrology Engineering, 17, 1221-1229.

Winchell, M., Srinivasan, R., Di Luzio, M., and Arnolad, J.G. (2009). ArcSWAT2.3.4 Interface for SWAT2005, User's Guide, Grassland, Soil and Water Research Laboratory, Temple, TX. 